\title{
Proposing RSFCA- Reliable Stress Factor Calculation Algorithm for Human Brain
}

\author{
Rajwinder Kaur \\ Department of Computer \\ Science \& Engg \\ Sri Sai College of \\ Engg and Technology, \\ Mannawala (Amritsar), \\ Punjab (India)
}

\author{
Jayant Shah Singh \\ Department of \\ Computer Science \& Engg \\ Guru Arjan Dev \\ Polytechnic College, \\ Dhariwal (Gurdaspur) \\ Punjab (India)
}

\author{
Kawaldeep Kaur \\ Department of \\ Computer Science \& Engg \\ Sri Sai College of \\ Engg and Technology, \\ Mannawala (Amritsar), \\ Punjab (India)
}

\begin{abstract}
Problem: The ratio of stress becomes increases due to several different environmental factors that may either effecthuman behavior directly or indirectly.

Purpose:Authors purpose to study different environmental factors that may effect on human behavior. The motivation towards writing on this topic is to find out the real causes (or symptoms) of stress on human brain. In addition, this paper also discussed how stress will damage human immune system. The significance to study this concept is to reduce the human death rate due to stress only.
\end{abstract}

Methodology: This paper designed a new algorithm "RSFCA" that is termed as a Releaiable Stress Factor Calculation Algorithm" on human brain while analyzing the different-2 situations. Here, authors use a primary data collection technique for the detection of real causes of stress on different categories of people viz. students, employees and business man.

Findings: Try to utilize body and brain tools for reducing the amount of stress on human brain. For handling critical situations effectively we have need to reduce stress and becomes a mandatory factor.

\section{Keywords}

Stress factor, stress causes, stress effects, stress cycle, stress reaction, Human behavior, human brain, human nervous system.

\section{INTRODUCTION}

Stress is inescapable part of modern life and most importantly exists in most of the people life viz. stress on student, stress on employee $\mathrm{s}$ and stress on business man etc. It is considered as a kind of social dynamic factor [18] that may change due to changing the need of life styles. A normal human being basically has 4 brain stages than can be shown in figure 1 :

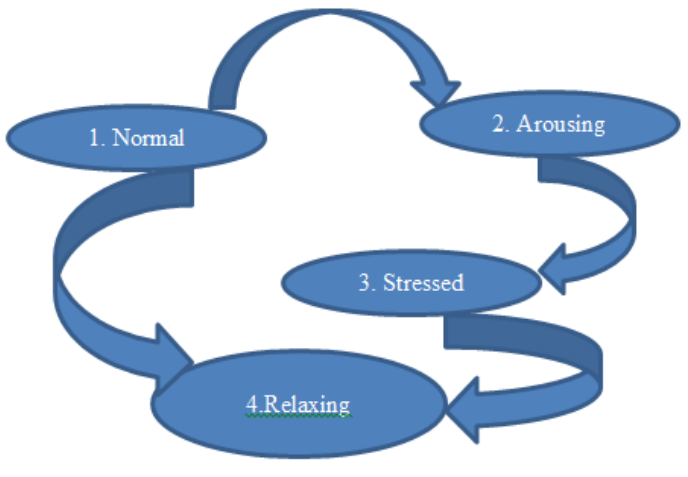

Fig.1: Human Brain Stages

The nature of stress may affect humans either positively or negatively but that depends on the vision of people how they consider this in their daily routine tasks. Here, authors are considering an example of stress on workplace [12] [21]. Pressure of work in organizations may affect positively for those employees who actually interested to learn from the environment (i.e. they want to learn something from the environment and would like to work under deadlines) and for rest of the people the same thing impacts negatively because of they feel deadline is a kind of pressure or stress on their minds.(In short, everything depends on the person attitude either he or she is interested to work or not as an example interested people accept new tasks as a challenges and noninterested people accept the same task as a burden or ballah ballah). The most important thing to discuss in stress psychology is its reflection in the form of stress reaction that can be easily shown in human behavior as an example tension, frustration, inability to concentrate and variety of physical symptoms that may include headache and fast heart beat [15]. Such kind of symptoms slowly-2 reduce humans brain cells [17] and ultimately the speed of brain functions will get slow down and hence it effects or destroy (damage) human nervous system and gave hazards results that can be given in table1.

Table.1: Stress Causes Several Diseases

\begin{tabular}{|c|c|c|c|}
\hline 5.10 & Name of the Disease & Effect on Human Nervous System & Stress Level on Himman Brain \\
\hline 1 & Dibbets & On eyes of legs & Very Highth \\
\hline 2 & Blood Pressure & Pulserate high & High \\
\hline 3 & Heart Attadk & Pulserate high & Moderate high \\
\hline
\end{tabular}


Each disease go through from the journey of stress as shown in figure 2 :

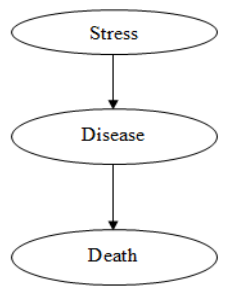

\section{Fig.2: Journey of Stress}

As authors surveyed the main cause of stress is the variations in hormones according to environmental changes [19] [3] that can be discussed with the help of a daily life example like the root cause of any type of stress is Problem that was originated from the environment as an example stress due to illness or stress due to some official work that can be counted under some specific range like inside the shear (tolerable) or outside the shear (i.e. Non-tolerable) [16] etc. As authors noticed the range of out of the shear people is going to be increases rapidly as the time passes.Any type of stress causes several diseases like infectious diseases, conflict injuries, anxiety \& depression [10] [15]. Such types of diseases create a mental disorder [14] and so called stress related illness[10] and effects human life since long [11]. So, to save human life from stress and provide protection with healthier environment is author's responsibility. By studying variety of different methods authors may help for reducing the mental level stress that can be listed below:

- Early in the morning meditation may help to reduce stress and correspondingly it provide self-relaxation for improving memory [8] [20] [5].

- Listening to music also reduce stress up to some extent [6].

- While diverting concentration from one to another [2][9].

- Time management creates a bridge between personal and professional life that ultimately helps to reduce stress. (Real Life experimental approach).

- Physical activities and daily games may reduce stress [1].

By following the author's advice (i.e. above discussed methods) the level of stress may reduce up to some extent and that results lifelong learning and aging [4].

This paper designed a new method "RSFCM" that is termed as a Reliable stress factor calculation method. This proposed methodologyprovidesself-compassion [9]. The benefit to utilize this proposed methodology is it considers different parameters for calculating different types of stress viz.psyclogical stress, mental stress, emotional stress and behavioral stress etc that can be discussed below while considering several different parameters with several different cases. These different cases considered different situations for calculating either the same type of stress in different situation as shown in table 2:
Table.2: Calculate stress on different categories of people while analyzing same situation.

\begin{tabular}{|l|l|l|l|l|}
\hline Category of Human & $\begin{array}{l}\text { Current } \\
\text { Situation }\end{array}$ & Type of Music & State of Mind & $\begin{array}{l}\text { \%age of Stress } \\
\text { Factor on Human } \\
\text { Brain }\end{array}$ \\
\hline Youngster(Lover) & $\begin{array}{l}\text { Recent Break- } \\
\text { Up }\end{array}$ & Listen Sad Songs & Too stressed & Very High \\
\hline Youngster(Lover) & $\begin{array}{l}\text { Beginning of } \\
\text { love }\end{array}$ & $\begin{array}{l}\text { Listening Romantic } \\
\text { Songs }\end{array}$ & Feeling Exciting & Relaxed(Calm) \\
i.e. no stress
\end{tabular}

Or different type of stress in same situation that can be shown with the help of different cases from 1 to 5 having table description from table. 3 to table.7:

Different cases for calculating stress:

Case 1(For Mental Stress): Mental stress may consider different types of daily life tensions as an example it either may related to job or related to family. Such kind of stress can be easily reflected through human facial expressions. A daily life example is you called somebody he or she is sitting inside you but not responding or in his or her thought process or planning etc.

\section{Table.3: Nomenclature for calculating Mental Stress.}

\begin{tabular}{|l|l|}
\hline CS & Critical Situation \\
\hline T & Time \\
\hline
\end{tabular}

Formulae for calculating Mental Stress:

$\mathrm{SF}=(\operatorname{cs} 1+\mathrm{cs} 2 \ldots \ldots+\mathrm{csn})(\mathrm{t} 1+\mathrm{t} 2+\ldots .+\mathrm{tn}) \quad$ Equation. 1

Case 2(For Emotional Stress): For calculating emotional stress authors considers a case of recent break-up between lovers.They calculated how stress response or reflects on human behavior especially when the situation is too critical.

Table.4: Nomen clature for calculating Emotional Stress during recent break-up.

\begin{tabular}{|l|l|}
\hline CS & Critical Situation \\
\hline SRe(H,M,L) & Stress Response(High, Moderate, Low) \\
\hline HB(N,AB) & Human Behavior(Nomal, Abnomal) \\
\hline
\end{tabular}

Formulae for calculating Emotional Stress Recent break-up:

SRe $[\mathrm{H}, \mathrm{M}$, and $\mathrm{L}]:=\mathrm{CS}(\mathrm{HB}[\mathrm{N}, \mathrm{AB}])$ Equation.2

Case 3(For Behavioral Stress): For calculating behavioral stress authors considers an example of any workplace such as multi-national companies. They want to check the performance of employees while working under pressure or working in friendly or stress free environment. 


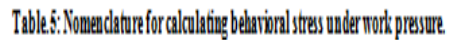

\begin{tabular}{|c|c|}
\hline$\overline{D E}$ & Dosyling \\
\hline QOWN & Qunstity oftlodid \\
\hline ID & Tim:Duration \\
\hline $\mathbb{P}$ & Bimen Pefiomence: \\
\hline
\end{tabular}

$\mathrm{DE}=\mathrm{QOW} / \mathrm{TD}$

Equation.3

DE $\alpha$ HP. (Human performance can be easily calculated through deadlines).

If task will be completed before the deadline that indicates there is no pressure on their mind otherwise there is a lot of pressure on their minds.

Case4 (For Psychological Stress): It can be easily calculated on work places on the basis of employee experience.

Table.6: Nomenclature for calculating psychobgicalstress.

\begin{tabular}{|l|l|}
\hline DE & Dasalina \\
\hline QOW & Quantity of Work \\
\hline TD & Time Dusation \\
\hline HP & Human Pefomance \\
\hline YOE & Yeass of Experiance \\
\hline
\end{tabular}

$\mathrm{DE}=\mathrm{QOW} / \mathrm{TD}+\mathrm{YOE}$

Equation.4

Case 5 (Overall Stress / Stress $_{\mathrm{Agg}}$ ): The aggregate of four separate types of stress cause "stress illness" that ultimately damage human immune system.

Stress $_{\text {Agg }}:=$ MS+ES+BS+PS

The motivation towards this new designed method is to reduce the death rate of humans due to stress.. Hence, this new designed methodology reduce death rate of human up to some extent and work for improving human life quality that some professionals may called human life extension technology(HLET). In this way, author's contributes their efforts for overall improvement of quality of life(QOL).

\section{PROPOSED PROCEDURE: RSFCA (RELIABLE STRESS FACTOR CALCULATION ALGORITHM)}

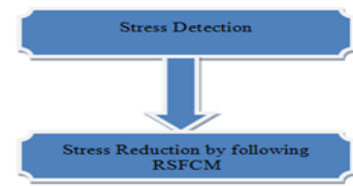

Figure 3: Steps Enabled for RSFCA.

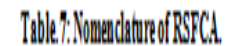

\begin{tabular}{|c|c|}
\hline $\mathbb{N}$ & 56 \\
\hline$M$ & Sampration \\
\hline Min: & Stanfredy: \\
\hline$b_{4}$ & Sershyes: \\
\hline TOALPRBDY & 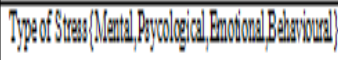 \\
\hline BMC & 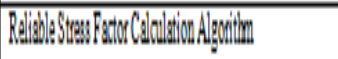 \\
\hline $\mathbb{E} \mid(|\mathrm{WB}|$ & 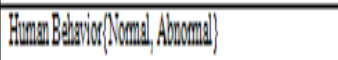 \\
\hline
\end{tabular}

RSFCA(SC,SF,S $\%_{\text {age, }}$ TOS $\{$ MS,PS,ES,BS $\left.\}, S R, H B\{N, A B\}\right)$

Step-1) SEARCH for SC.

Step-2) THEN CALCULATE TOS \{MS, PS, ES, BS \}.

For calculating MS, Apply equation 1.

For calculating ES, Apply equation 2.

For calculating BS, Apply equation 3.

For calculating PS, Apply equation 4.

Step-3) After that Calculate Stress $_{\mathrm{Agg}}=£(\mathrm{MS}+\mathrm{PS}+\mathrm{ES}+\mathrm{BS})$.

Step-4) at the end, Calculate $S_{\% \text { age. }} / /$ it includes the sum of all different types of stresses on human brain

S\%age: $=$ Type of stress*100/Sagg.

Step-5) $\operatorname{IF}(25<$ S\%age $<35)$

\{

$\mathrm{HB}:=\mathrm{N}$.

\}

ELSE

\{

$\mathrm{HB}:=\mathrm{ABN}$.

\}

Step-6) Hence, SR: = HB //Hence stress reaction is directly reflects through human behavior.

\section{RESEARCH DESIGN}

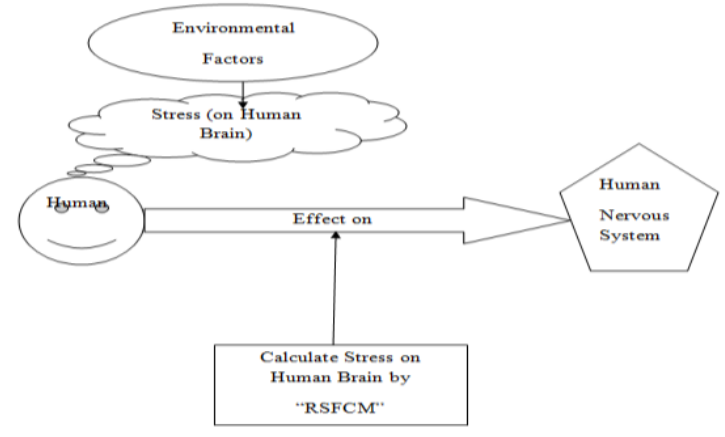

Figure.4: Causes of Stress 


\section{STRESS CYCLE}

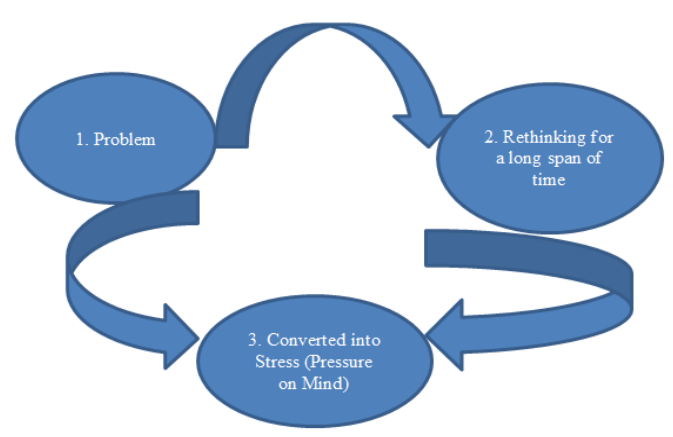

Figure.5: Steps Enabled in Stress Cycle.

\section{CONCLUSIONS}

Different types of stress, either directly or indirectly effects on human behavior. This rapidly increased growth of stress on human brain may be reduced either by time management or by following separate methods suggested above in this paper. The new designed methodology is termed as "RSFCA" (Reduced Stress Factor Calculation Algorithm) that helps to calculate the overall stress on human brain while analyzing different situations on separate categories of people say stress on students, stress on employees and stress on business man etc. The main focus of authors is to build a bridge between personnel and professional life that ultimately approach to a balanced life \& also provides healthier environment for better living. Hence, this proposed methodology helps to extend human life (i.e. it supports to human life extension technology) that ultimately reduce death rate that only causes by stress.

\section{REFERENCES}

[1]Frits A.J Muskid, Charles L.Raison \&leo Purimboom, 2015. Physical activity Protects Human brain against metabolic stress induced by a postprandial \& chronic inflammation, Behavior Neurobiology.

[2]Shawn Achor, Alia J.Crum \& Peter salovery, November 2013. Rethinking stress:The role of mindsets in determining the stress response, Journal of personality and social psychology.

[3]T.E Schramek, A.Fiocco, M.Tu \& F.Maheu, 2007. The effects of stress and stress harmones on human cognition: Implifications for the field of brain \& cognition, ELSEVIER.

[4]Understanding the brain: The birth of learning science new insights on learning through cognitive and brain science, Thesis- CERI (Centre of Education Research \& Innovation).

[5] Priya Utama \& Mingqian Lui, June 2014. Meditation effect on human brain compared with psychological human questionnaire Journal of information and education technology.
[6]M.Nater,Ulrike Ehlert\& Linda Finkel,The effect of music on human stress response, PLOS.

[7]Jung-Tae Lee \& Ssang-hee seo, March 2010.Stress \&EEG, Source: Convergence \& hybrid information technologies book edited by marrius crisan, kore.

[8]Lawrence W.Barsalou \&Wendy hasenkamp, March 2012.Effects of meditation experience on functional connectivity of distributes brain network, Frontiers in human neuroscience, USA.

[9]Marilyn Ostergren, Alferd W.Kaszinak \& Jacob o.Wobbork, 2012. The effects of mindfulness meditation training on multi-tasking in a high stress information environment, Journal of graphics interface,USA.

[10]Mathew Cordova,ScottR.Bishop and John a.Astin,2002.Mindfulness-based stress reduction for health care professionals: Results from a Randomized Trial ,International journal of stress management.

[11]Stress in the workplace-meeting the challenge, Indian Health Deptt, Health advocate Inc.

[12]Aleta Meyer, February 2015. Self-regulation and toxic stress: A Review of ecological, biological and developmental studies of self-regulation and stressthesis.

[13]Natalia sidorova, Mykola Pechenizkiy, What is your current stress level?Detection of stress patterns from GSR Sensor data.

[14]Kazuhito Roktan \& Testuro Ohmori, Rylyikaji, 2004. Stress control and human nutrition, Journal of medical investigation.

[15]Uma devi.T, October 2011.A Study on stress management \& coupling strategies with reference to IT Companies, Journal of information technology and economic development.

[16]https://en.wikipedia.org/wiki/stress-intensity-factor.

[17]www.youramazingbrain.org/.

[18]www.ncbi.nlm.nih-gov/books/NBK43737/.

[19]Paul J.Lucassen, Ai-Min Bao \& Dick F.Swaab, 2005. The stress system in the human brain in depression and neurodegeneration, Centre for neuroscience, ELSEVIER.

[20]Lawrence W.Barsalon \&Wendy hasenkamp, March 2012. Effects of meditation experience on functional connectivity of distributed brain network, Frontiers in humans neuroscience, USA.

[21]Selamawit Fisseha Tekeste \& Najmoddin affzada, Stress causes\& its management at work place, Thesis-2013, Umea School of business \& economics. 